\title{
Carbon Footprint of Surgical Masks Made in Taranto to Prevent SARS-CoV-2 Diffusion: A Preliminary Assessment
}

\author{
Pasquale Giungato ${ }^{1, *(\mathbb{D}}$, Roberto Leonardo Rana ${ }^{2} \mathbb{D}$, Nicole Nitti ${ }^{1}$, Cosima Cavallari $^{1}$ and Caterina Tricase ${ }^{2} \mathbb{C}$ \\ 1 Department of Chemistry, University of Bari, Taranto District-via Alcide de Gasperi, 74123 Taranto, Italy; \\ nicolenitti97@libero.it (N.N.); mimmacavallari@gmail.com (C.C.) \\ 2 Department of Economics, University of Foggia, 71121 Foggia, Italy; roberto.rana@unifg.it (R.L.R.); \\ caterina.tricase@unifg.it (C.T.) \\ * Correspondence: pasquale.giungato@uniba.it
}

\section{check for}

updates

Citation: Giungato, P.; Rana, R.L.; Nitti, N.; Cavallari, C.; Tricase, C. Carbon Footprint of Surgical Masks Made in Taranto to Prevent SARS-CoV-2 Diffusion: A Preliminary Assessment. Sustainability 2021, 13, 6296. https://doi.org/10.3390/ su13116296

Academic Editors:

Zenon Foltynowicz and

Anna Lewandowska

Received: 4 May 2021

Accepted: 25 May 2021

Published: 2 June 2021

Publisher's Note: MDPI stays neutral with regard to jurisdictional claims in published maps and institutional affiliations.

Copyright: (c) 2021 by the authors. Licensee MDPI, Basel, Switzerland. This article is an open access article distributed under the terms and conditions of the Creative Commons Attribution (CC BY) license (https:/ / creativecommons.org/licenses/by/ $4.0 /)$.

\begin{abstract}
The international outbreak of the SARS-CoV-2 infection has put pressure on governments to find immediate solutions to the shortage of surgical masks and other protective equipment. To allow textile manufacturers producing surgical masks to avoid usual restrictions imposed on personalprotective-equipment producers, the Italian government issued a ministerial decree that was followed by technical guidelines provided by several universities. Starting from a hypothetical composition and design, we calculated the carbon footprint of surgical masks manufactured following technical guidelines, with the city of Taranto hosting the production facility. Results show that the production of textile sheets composing the masks and their disposal were the main contributors to emissions, followed by packaging and transportation. A strategy of reuse based on laundry operation was modelled, and the balance between disposal strategy and reuse with the laundry operation (which has environmental issues due to detergents and water use) was in favor of the second option. To reduce the carbon footprint, a minimized textiles area (by smart shaping) and reuse strategies result in the best options. Further reduction may be achieved by building up a recycling chain of disposed masks, activated by municipalities.
\end{abstract}

Keywords: SARS-COV-2; surgical mask; carbon footprint; Taranto; washing; reuse

\section{Introduction}

At the end of 2019 in Wuhan (China), a virus belonging to the coronavirus family, now known as Sars-CoV-2, was identified in relation to a series of patients with severe acute respiratory syndrome. The disease for which this pathogen is responsible was named COVID-19 on 11 February 2020 by the Director-General of the WHO [1]. Due to its strong viral load, Sars-CoV-2 spread throughout China and subsequently to almost all parts of the world. Contagion occurs through close encounters with infected people; however, despite being a potentially deadly virus, the symptoms of the disease are not always severe, and a section of the sick population was asymptomatic, thus increasing the number of infected individuals. Italy was the second country to be severely affected in March 2020, and the entire country was placed under lockdown to contain the spread of the virus. One of the key points on which emergency management was based was prevention. Since the virus spreads mainly through droplets of saliva expelled while talking, coughing, or sneezing, the fundamental means of prevention are individual prevention devices. To help textile manufacturers that are producing surgical masks to avoid usual restrictions imposed on personal-protective-equipment producers, the government issued the "Cura Italia" decree on 17 March 2020 [2] through which, thanks to the derogation in Article 15, it became possible to produce and market surgical masks while avoiding the usual restrictions imposed on personal-protective-equipment producers. The intensive production of these masks involves their subsequent disposal and has environmental impact that needs to be analyzed. The literature in the field contains very few examples, except for a paper by 
Vozzola E. et al. [3] in which the LCA of isolation gowns used as sanitary equipment was carried out considering two possible alternatives: reusable (polyester-made) and disposable (polypropylene-made) isolation gowns. The paper demonstrated that, considering 1000 uses (functional unit), the reusable gown (by laundry operations including transportation) had lower environmental impact with respect to disposable equipment, although laundry operations created environmental issues due to water, detergents, and energy consumption. The key point was the impact associated with the production of isolation gowns occupying the largest part of their environmental impact. Rizan et al. [4] estimated the carbon footprint of gloves, aprons, face shields, and type IIR and IIIR surgical masks made of polypropylene, and their scenario modelling indicated that a carbon footprint could be avoided through local manufacturing, reducing glove use, and using reusable gowns and face shields with maximal recycling. Klemes et al. [5] reported the energy and environmental footprints of COVID-19 fighting measures, including masks and the carbon footprints of N95, surgical, and cloth masks, suggesting reuse as a valuable alternative that moves towards lowering energy consumption and the environmental footprint, provided that the effectiveness of the fighting measures was not compromised. A possible strategy to reduce the carbon footprint of the mask under study could be reuse by washing. The hypothesis was to carry out a washing of the type used in the pre-COVID-19 period for protective wear in hospitals [3], and recently analyzed concerning the loss of filtering power after a disinfection process by Liao et al. [6]. In the latter work, various disinfection schemes commonly used on TNT, obtained with melt-blowing technology, were studied, starting from initial particle-filtration efficiency greater than $95 \%$. Heating inactivates the virus in solution within $5 \mathrm{~min}$ at $70{ }^{\circ} \mathrm{C}$ and is among the most scalable and easy-to-use methods for viral disinfection. Heat $\left(\leq 85^{\circ} \mathrm{C}\right)$ at different humidity values $(\leq 100 \%$ relative humidity percentage, $\mathrm{RH}$ ) is the most promising and nondestructive method for preserving the filtration properties in nonwoven fabrics obtained with the melt-blowing technology used in masks of the type N95 (USA standard), corresponding as filtering power to FFP2 (European standard), KN95 (Chinese standard), DS/DL2 (Japanese standard), and KF94 (Korean standard). A paper by Juang et al. [7] on reuse after cleaning of N95 masks demonstrated that masks could be heated for $60 \mathrm{~min}$ at $70{ }^{\circ} \mathrm{C}$, retaining $98.5 \%$ of filtering efficiency; masks could also be boiled for $5 \mathrm{~min}$ and then air-dried, retaining $92.4 \%$ of their filtering efficiency. In both cases, elastic laces should be detached, and equivalent elastics restapled to the mask after treatment.

Using soap and water or medical-grade alcohol (as every liquid medium, as indicated by Liao et al. [6]) significantly decreases the filtering efficiency of masks by $54 \%$ and $67 \%$, respectively, due to the neutralization of electrets on the inner melt-blown layer of the masks. There is strong and scientifically supported evidence that the SARS-CoV-2 coronavirus would not survive after cleaning methods proposed as a remedy to shortages of masks, but no regulatory agency has approved the short- and long-term effects of N95 respirator reuse after cleaning [7]. A possible strategy of reuse would be to simply wait and reuse after 3 days, after evidence that the virus titer was greatly reduced from $10^{3.7}$ to $10^{0.6} \mathrm{TCID}_{50}$ per milliliter of medium after $72 \mathrm{~h}$ on plastics $\left(40 \% \mathrm{RH}\right.$ and $\left.21-23^{\circ} \mathrm{C}\right)$ [8], indicating an estimated median half-life of SARS-CoV-2 of approximately $6.8 \mathrm{~h}$ on plastics.

As there is a gap in the literature about the carbon footprint of surgical masks, particularly on the individuation of critical steps in their life cycle and possible remedies, in this paper, we analyzed the carbon footprint of the production and disposal of surgical masks hypothetically produced in the city of Taranto, with nonwoven fabrics produced in Italy. The composition and assembly of the masks were assumed to be compliant with the guidelines issued by the Milan Polytechnic [9] to allow for producers to conform to the ministerial decree, which allowed for production in derogation of the current regulations to deal with the lack of protective devices. We started with the transportation of the nonwoven fabrics from their production site (located in northern Italy) to the city of Taranto (Apulia region, in the south of Italy) where they are hypothetically assembled to produce masks that are to be packaged and transported to the final users in a $100 \mathrm{~km}$ range comprising the 
province of the city. Regarding the reuse strategies to reduce carbon footprint of the mask, we discarded reuse by manual individual washing, as this practice is only possible for cotton fabrics that are quite different from the polypropylene ones used in this work. Another recommended individual washing practice with a mixture of ethyl alcohol and water $75 / 25$ was not considered, as the work of Liao et al. [6] demonstrated a loss of filtering capabilities due to the neutralization of electrets, the enhancer of particle adsorption.

\section{Materials and Methods}

Analysis was conducted using OpenLCA software [10] and OpenLCA impact assessment methods [11] with the Ecoinvent 3.7 database [12]. The carbon footprint was determined according to ISO 14067:2018 [13] to evaluate greenhouse-gas emissions, as indicated in the Kyoto Protocol, released directly or indirectly from manufacturing of textiles (including polymer production) to transportation, use, and disposal (or laundry and subsequent disposal). The model used for the characterization step in LCA was IPCCGWP100, which is included in CML baseline impact-assessment methods to convert direct and indirect greenhouse gases into $\mathrm{CO}_{2}$ equivalents over a fixed period of 100 years. The LCA approach was followed according to international standards and guidelines [14,15], considering goal and scope definition, system boundary, life-cycle inventory (LCI) analysis, life-cycle impact assessment (LCIA), and life-cycle interpretation. The goal of the work was to compare the environmental impact of a single-use surgical mask made with a polypropylene nonwoven fabric and a reusable mask washed in an industrial laundry facility to prevent the transmission of infection in Italy. The scope of the work was to model two scenarios for the public use of face masks. In the case of disposable masks, we identified as the functional unit one surgical mask produced according to ministerial decree "Cura Italia", starting from raw textiles produced in Italy, followed by transportation to the assembly site (Taranto), use, and disposal by waste incineration of the plastic fraction in municipal solid waste with energy and metal recovery. As a secondary approach, we hypothesized the reuse of masks by washing in an industrial laundry facility. In this second case, the functional unit was one use of the mask that was the same as the single-use disposable mask. The weight of the surgical mask was calculated by adding the tissue mass (computed from the dimensions and area mass of the textile) that composed its different layers. Table 1 reports the characteristics of the examined surgical mask. The washable mask was to undergo 10 washings before being incinerated. For the packaging, we assumed a cardboard box that contained the masks wrapped in a polyethylene foil, assuming that $95 \%$ of the packaging consisted of a cardboard box, while $5 \%$ of the polypropylene packaging film and packaging represented $16 \%$ of the overall weight of the mask, following assumptions made in [3]. After the use phase, packaging disposal (cardboard box and packaging film composed of low-density polyethylene) was to be performed by incineration in a municipal solid-waste plant with energy and metal recovery, which is the base scenario used in the city of Taranto. Transportation was computed assuming the distance from the textile-production facility to Taranto with a small lorry with a max payload of $5 \mathrm{t}$. The produced masks were to be packaged and transported to the final users in a $100 \mathrm{~km}$ range comprising the province of the city. No modelling of transportation was made for the polymer granulate, as it was supposed that raw materials for the manufacturing of the nonwoven textiles came from Italy. The system boundary of the study is reported in Figure 1. Manufacturing energy consumption for both elastic laces (made of synthetic rubber) and the aluminum strip for nose adherence (sewing and packaging) is reported in Table 1. Waste and its treatment arising from mask manufacturing was not modelled due to limited data, but it was presumable that its impact would be negligible in the modelled scenario. Emissions from the life cycle of the factory were also not modelled for the same reasons, as equipment is assumed to have a long lifespan (several decades), and emissions and the environmental impact associated with the fabrication and decommission of equipment would be proportionally allocated, resulting in a negligible amount. The used energy mix was the Italian energy grid mix. The mask under examination was assembled by 
composing four layers of TNT textiles to ensure enough margin to be considered useful for personal protection against SARS-CoV-2. The mask modelled in this study conformed to the EN 14683:2019 norm [16], a European standard not applicable to masks intended exclusively for the personal protection of sanitary staff. The mask modelled in the present study, with the technical characteristics reported in Table 1, is similar to an IIR type described by the aforementioned norm.

Table 1. Characteristics of surgical polypropylene mask modelled in this paper.

\begin{tabular}{lc}
\hline Textiles & Four Layers of Spun-Bond Polypropylene ${ }^{\mathbf{1}}$ \\
\hline Area mass (g/m ${ }^{2}$ ) & $40^{2}$ \\
Dimensions (mm) & $180 \times 180^{2}$ \\
Mass (g) & $5.184^{2}$ \\
Elastic laces (g) & $0.45^{3}$ \\
aluminum strip (g) & $0.23^{3}$ \\
Packaging film (g/apiece) & $0.08^{4}$ \\
Cardboard box (g/apiece) & $1.56^{4}$ \\
Manufacturing (kWh/kg) & $0.296^{3}$ \\
Transportation of textile (km) & $980^{2}$ \\
Bacterial filtration efficiency (\%) & $100^{2}$ \\
Differential pressure (Pa/cm $\left.{ }^{2}\right)$ & $59^{2}$ \\
\hline
\end{tabular}

Source: ${ }^{1}[12] ;{ }^{2}[9] ;{ }^{3}[4] ;{ }^{4}[3]$.

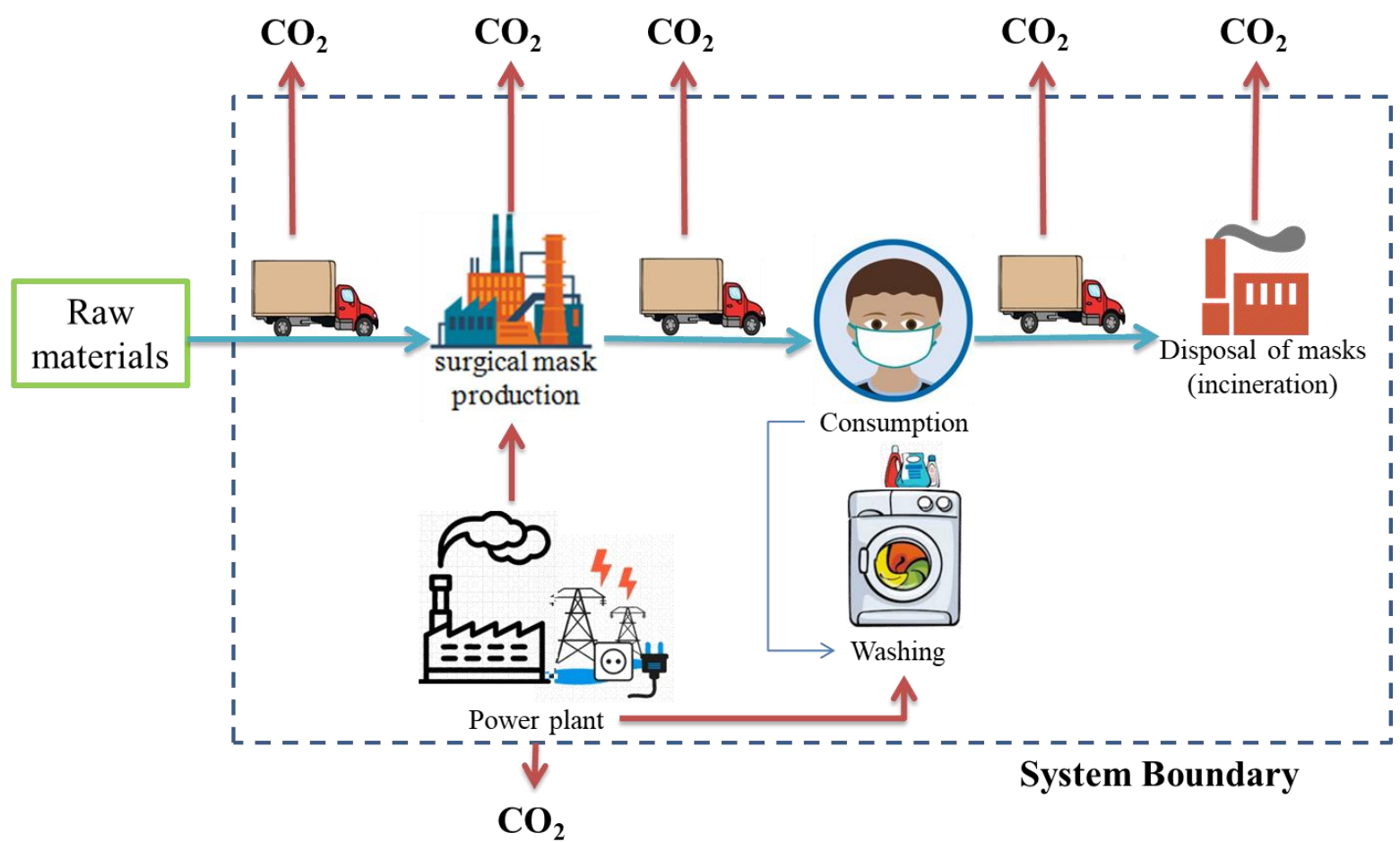

Figure 1. Study system boundary.

In this paper, the examined washing process was a wet process comprising washing, drying, and finishing in a low-capacity industrial laundry facility (300-500 kg of laundry per $8 \mathrm{~h} /$ batch). The capacity of this service is typically between 8 and $12 \mathrm{~kg}$ of masks per batch. At the end of washing, the mask is ironed using heated cylinder ironers. The used dataset includes the infrastructure (washer and dryer, building) necessary for the operation of the service and includes all necessary inputs (water, electricity, and heat, detergent for cleaning) to perform the service, modeling washing and drying, and including energy, water, detergent, and necessary infrastructure "from the cradle" (i.e., including all upstream activities) $[17,18]$. According to the cited literature data, the mask could be washed 10 times 
before the TNT fibers lose the filtering capacities necessary for classification in type IIR. Assuming 10 uses, a change of functional unit is also necessary, so to refer to a single use, it is necessary to divide the obtained carbon-footprint value by 10 .

\section{Results}

The carbon footprint of a surgical mask produced according to the abovementioned guidelines is $32.7 \mathrm{~g} \mathrm{CO}_{2}$ eq. per mask, with process contributions given in Figure 2. This result aligns with the mentioned work on gowns [3], as emissions are about $3.60 \mathrm{~g} \mathrm{CO}_{2}$ eq. per $\mathrm{g}$ of mask versus $5.58 \mathrm{CO}_{2}$ eq. per $\mathrm{g}$ of gown in this work. Data are also in agreement with those of Rizan et al. [4], who estimated a range of 22-31 $\mathrm{g} \mathrm{CO}_{2}$ eq. per mask (type IIR and IIIR surgical masks made of polypropylene), and of Klemes et al. [5], who reported $59 \mathrm{~g} \mathrm{CO}_{2}$ eq. per mask. Allison A.L. et al. [19] reported $59.5 \mathrm{~g} \mathrm{CO}_{2}$ eq. per mask, which is slightly higher but in the same order of magnitude. Most greenhouse-gas emissions came from textile production (44\%), followed by mask disposal (40\%). The remaining is allocated to the production of the cardboard box composing the packaging, followed by the transportation of the fabrics to the site of sewing and electricity used for assembling and sewing of the final product. Some other processes, such as the disposal of the plastic film that makes up the packaging, are negligible. These results pose a serious issue in the choice of material, which is crucial in lowering the environmental impact of masks considering their production, disposal, and recycling. Accordingly, the weight of the final product would play an important role in determining the carbon footprint, and the obliged technical requirements using spunbonded polypropylene textiles, as can be seen in Figure 3. The construction of the mask involves the treatment of a $180 \times 180 \mathrm{~mm}$ rectangle of textiles into a pleated final wearable mask of $180 \times 90 \mathrm{~mm}$; shrinkage is due to pleating. Pleating is required both to permit droplets emitted from nearby people to slide downward, preventing ingestion into the lung system of the mask owner, and to adapt the mask to the face physiognomy of the owner; in this case, for nonsanitary operators, this technical requirement does not have to be so stringent, and a more accurate shaping of the mask to reduce the area can be accomplished. Shape re-engineering is essential to reduce the masks' carbon footprint without compromising the prevention capabilities, and a $50 \%$ in the carbon footprint can be accomplished by halving the area of the initial mask. Shape conformation that could reduce the textile area extending toward the cheekbones, which is unusable, is preferred. The carbon footprint drops by reducing layers or surface area, but the critical point is to ensure the same filtration performance and structure stability; for this reason, every structure made by different layers or areas of the mask should be tested to ensure that the filtration and structural performance meets the requirements for dedicated use. In this respect, a balance between filtration efficiency, structural performance, and environmental impact should be achieved.

In the face of a net decrease in the carbon footprint for the single use of the mask, the contribution of polymer production ends up being almost on par with respect to the washing process and its environmental load due to consumed energy, impact of detergents, and used water, and the impact of the disposal of the spent mask. Despite everything, for a single use, the washing procedure enables a reduction in the carbon footprint of the reused mask, compared with the disposable one, by $85 \%$. This reduction is due to the considerable load capacity of a washing machine capable of dealing with large quantities of masks per washing cycle. 


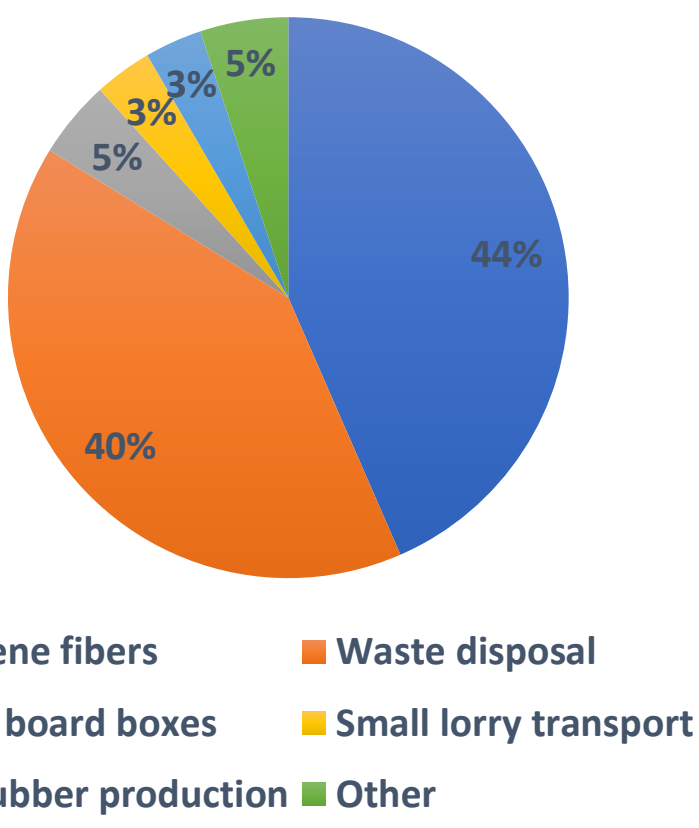

Figure 2. Process contribution to carbon footprint of the surgical masks (percentage) made in PP.

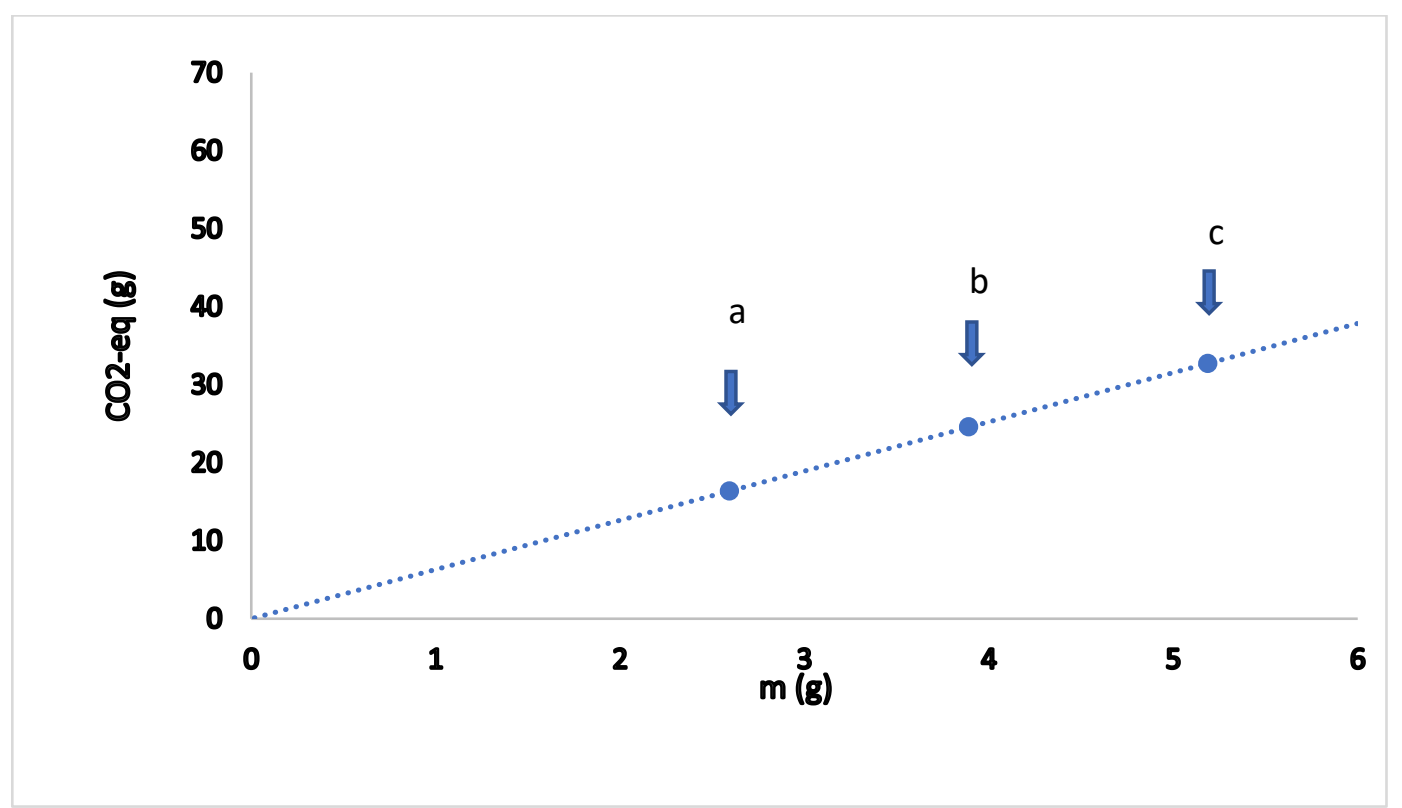

Figure 3. Carbon footprint versus mass of surgical masks made in PP and dependence upon pleating: $a=$ mask without pleating, $\mathrm{b}=$ mask with average pleating, $\mathrm{c}=$ mask with pleating.

Regarding the mask that is the subject of this study, carrying out 10 industrial washes generated a carbon footprint of $4.906 \mathrm{~g} \mathrm{CO}_{2}$ equivalent for a single use of the mask. As a comparison, Allison A.L. et al. [19] reported a value of $4.13 \mathrm{~g} \mathrm{CO}_{2}$ equivalent for a single use of the mask using average household machine washing, assuming as a functional unit a full machine wash every 3 days, which equates to each mask being washed 122 times in one year. The percentage contribution of the processes is illustrated in Figure 4. 


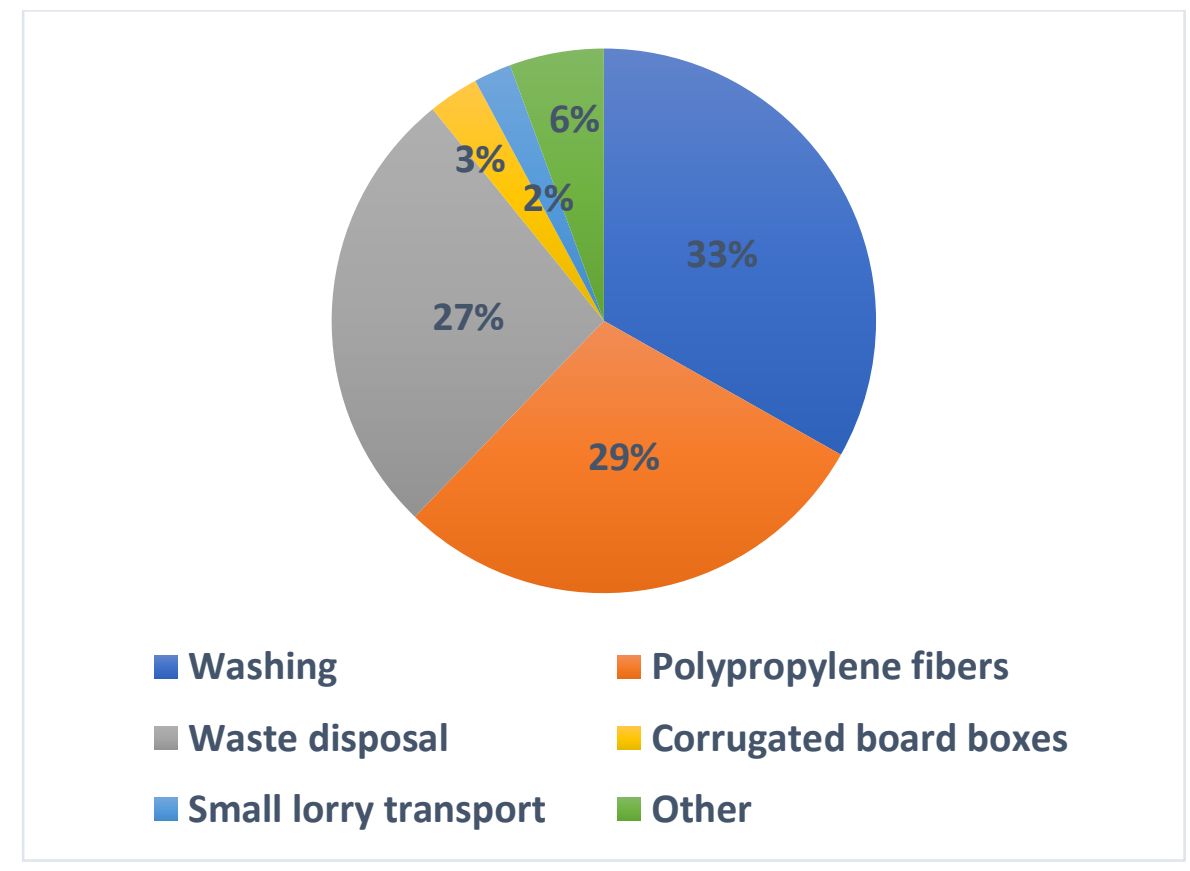

Figure 4. Process contributions to carbon footprint of surgical masks (percentage) made in PP and washed 10 times in an industrial washing machine.

\section{Discussion}

Most of the carbon footprint of the examined surgical mask comes from textile production, starting from raw materials (granulate) and ending with nonwoven fabrics, followed by disposal. Transport, packaging, and assembly contributions are negligible. The remaining packaging is waste, incinerated in a municipal solid-waste incinerator, and the recycling of aluminum strips is assumed to happen in the incinerator. Nowadays, there is no recycling chain of the disposed surgical masks built up from the municipalities. The reasons for these choices come from a report from the Italian Istituto Superiore di Sanità (Higher Institute of Health) that provides recommendations for the management of disposable masks produced by household and non-household users, including public and private, commercial, and manufacturing entities, other than health, and social and healthcare activities [20]. This report suggested including masks coming from households in the European List of Waste Code EER 200301, such as urban waste to be included in unsorted waste. All others are classified under EER 150203 "absorbents, filter materials, rags and protective clothing, other than those mentioned in 150202", as they belong to the special-waste category. Government pressure in facing the pandemic has increased the consumption of masks and skyrocketed global production using polymeric materials in an unprecedented manner, with the following risks due to pollution from microplastics [21]. There is no complete information on how much Italians are spending on masks because distribution channels are uneven: pharmacies and para-pharmacies, supermarkets, and tobacconists. Data on pharmacies and para-pharmacies collected by a survey company clearly showed, from the beginning of 2020 until the end of September, 98 million euros spent by families on masks in this channel alone. In September, in this channel, about 13 million surgical masks were bought per day (considering also that the government fixed the maximal price at 50 cents apiece), and it is plausible that supermarkets and tobacconists sold at least as many [22]. In schools, about 11 million masks are distributed free of charge every day, to which those distributed to public and private institutions should be added. The recycling of the polypropylene of nonwoven textiles, aluminum strips, and elastic laces may highly contribute to the carbon-footprint mitigation of the entire life cycle of surgical masks used to prevent SARS-Cov-2 diffusion. Washing seems to the best option 
immediately available to reduce greenhouse-gas emissions, provided that a collection chain of spent masks is active.

\section{Conclusions}

The carbon footprint of the production and disposal of surgical masks hypothetically produced in the city of Taranto using the LCA was studied, considering composition and assembly to be compliant with the guidelines issued by the Milan Polytechnic. We started with the transportation of the textiles from the production site (located in northern Italy) to the city of Taranto (Apulia region), where they were hypothetically assembled to produce the masks that were to be packaged and transported to the final users in a $100 \mathrm{~km}$ range in the province of the city. The computed value of $32.7 \mathrm{~g} \mathrm{CO}_{2}$ eq. per mask included the main contributors of greenhouse-gas emissions coming from textile production, followed by disposal, the production of the cardboard box composing the packaging, and transport of the fabrics to the site of sewing and assembling the final product. Considering that, in Italy, the consumption of masks to prevent SARS-CoV-2 diffusion is estimated at several millions a day, a slight reduction in the carbon footprint of surgical masks may result in a huge reduction in national greenhouse-gas emissions. Washing in an industrial laundry facility seems to be the best option for carbon-footprint abatement, provided a collection chain of spent masks is built up. The procedure enables a reduction in the carbon footprint of reused masks, compared with that of disposable ones, by $85 \%$ per single use due to the considerable load capacity of the washing machine. Shape re-engineering, research for less impactful materials, and reuse with washing are essential to reduce the carbon footprint of the masks without compromising contagion-prevention capabilities. Future developments of this work could include evaluations of the carbon footprint of surgical masks and other protective equipment in the case of textile recycling, and the implementation of new and innovative materials that are better susceptible to recycling and with minor environmental impact.

Author Contributions: Conceptualization, P.G.; data curation, P.G., N.N., and C.C.; funding acquisition, P.G.; methodology, P.G., R.L.R., and C.T.; supervision, P.G., R.L.R., and C.T.; writing-original draft, P.G., R.L.R., and C.T.; writing-review and editing, P.G., R.L.R., and C.T. All authors have read and agreed to the published version of the manuscript. Portions of this research were prepared while N.N. and C.C. were students in thesis at University of Bari Aldo Moro, Bachelor Degree in Environmental Science, under the supervision of P.G.

Funding: This research was funded by University of Study Aldo Moro, fondo ordinario ricerca scientifica 2016/2017. The APC was funded by discount vouchers.

Conflicts of Interest: The authors declare no conflict of interest.

\section{References}

1. WHO. Coronavirus Press Conference 11 February, 2020. Available online: https://www.who.int/docs/default-source/coronavi ruse/transcripts/who-audio-emergencies-coronavirus-full-press-conference-11feb2020-final.pdf?sfvrsn=e2019136_2 (accessed on 18 July 2020).

2. Ministerial decree n. 18 ("Cura Italia" published on March 17, 2020 in the Official Bulletin n. 70). Misure di potenziamento del Servizio Sanitario Nazionale e di Sostegno Economico per Famiglie, Lavoratori e Imprese Connesse All'emergenza Epidemiologica da COVID-19. Available online: https:/ / www.gazzettaufficiale.it/eli/gu/2020/03/17/70/sg/pdf (accessed on 18 July 2020).

3. Vozzola, E.; Overcash, M.; Griffing, E. Environmental considerations in the selection of isolation gowns: A life cycle assessment of reusable and disposable alternatives. Am. J. Infect. Control. 2018, 46, 881-886. [CrossRef] [PubMed]

4. Rizan, C.; Reed, M.; Bhutta, M.F. Environmental impact of Personal Protective Equipment distributed for use by health and social care services in England in the first six months of the COVID-19 pandemic. MedRxiv 2021. [CrossRef]

5. Klemeš, J.J.; Fan, Y.V.; Jiang, P. The energy and environmental footprints of COVID-19 fighting measures—PPE, disinfection, supply chains. Energy 2020, 211, 118701. [CrossRef] [PubMed]

6. Liao, L.; Xiao, W.; Zhao, M.; Yu, X.; Wang, H.; Wang, Q.; Chu, S.; Can, Y. N95 Respirators Be Reused after Disinfection? How Many Times? ACS Nano 2020, 14, 6348-6356. [CrossRef] [PubMed]

7. Juang, P.S.C.; Tsai, P. N95 Respirator Cleaning and Reuse Methods Proposed by the Inventor of the N95 Mask Material. J. Emerg. Med. 2020, 58, 817-820. [CrossRef] [PubMed] 
8. $\quad$ van Doremalen, N.; Bushmaker, T.; Morris, D.H.; Holbrook, G.M.; Gamble, A.; Williamsom, M.P.H.; Brandi, N.; Tamin, A.; Arcourt, J.L.; Thornburg, N.J.; et al. Aerosol and surface stability of SARS-CoV-2 as compared with SARS-CoV-1. N. Engl. J. Med. 2020, 382, 1564-1567. [CrossRef] [PubMed]

9. Milan Polytechnic, Nota Tecnica v 5.0 del 4 May 2020. Available online: https://www.regione.lombardia.it/wps/wcm/connect /0c81f5f1-ef90-4417-afe2-8d659c21b4ab/NOTA+TECNICA+2-1+-+Scheda+materiali+approvati.pdf?MOD=AJPERES\&CACH EID=ROOTWORKSPACE-0c81f5f1-ef90-4417-afe2-8d659c21b4ab-n4n8iMs (accessed on 20 January 2021).

10. OpenLCA vers. 1.6.3. Available online: www.openlca.org (accessed on 1 July 2020).

11. OpenLCA Impact Assessment Methods 2.0.5. Available online: https://nexus.openlca.org/database/openLCA\%20LCIA\%20me thods (accessed on 1 July 2020).

12. Wernet, G.; Bauer, C.; Steubing, B.; Reinhard, J.; Moreno-Ruiz, E.; Weidema, B. The ecoinvent database version 3 (part I): Overview and methodology. Int. J. Life Cycle Assess. 2016, 21, 1218-1230. Available online: http://link.springer.com/10.1007/s11367-016-1 087-8 (accessed on 12 October 2020). [CrossRef]

13. ISO. 14067:2008 - Greenhouse Gases_Carbon Footprint of Products-Requirements and Guidelines for Quantification. International Organization for Standardization; International Organization for Standardization: Geneva, Switzerland, 2008.

14. ISO. 14040:2006 —Environmental Management_LCA—Principles and Framework; International Organization for Standardization: Geneva, Switzerland, 2006.

15. ISO. 14044:2006-Environmental Management_LCA—Requirements and Guidelines; International Organization for Standardization: Geneva, Switzerland, 2006.

16. European Standards. Medical Face Masks—Requirements and Test Methods; EN 14683; European Standards: Pilsen, Czech, 2009.

17. Máša, V.; Bobák, P.; Stehlík, P.; Kuba, P. Energy Intensive Process in Professional Laundry Service: Up-to-date Approach. Chem. Eng. Trans. 2013, 35, 259-264. [CrossRef]

18. Máša, V.; Bobák, P.; Kuba, P.; Stehlík, P. Analysis of energy efficient and environmentally friendly technologies in professional laundry service. Clean Technol. Environ. Policy. 2013, 15, 445-457. [CrossRef]

19. Allison, A.L.; Ambrose-Dempster, E.; Domenech Aparsi, T.; Bawn, M.; Casas Arredondo, M.; Chau, C.; Chandler, K.; Dobrijevic, D.; Hailes, H.; Lettieri, P.; et al. The impact and effectiveness of the general public wearing masks to reduce the spread of pandemics in the UK: A multidisciplinary comparison of single-use masks versus reusable face masks. UCL Open Environ. Prepr. 2020. [CrossRef]

20. Istituto Superiore di Sanità. Interim Guidance to Manage Disposable Facial Masks and Gloves Coming from Household and Non-Household Sources, Version May 18, 2020. COVID-19 ISS Working Group Environment and Wastes (In Italian). Available online: https: / www.iss.it/documents/20126/0/20200519+Rapporto+ISS+COVID-19+n.+26_2020.pdf/221a18a2-1de8-5e34e577-2a121baaa231? $\mathrm{t}=1589885416433$ (accessed on 21 October 2020).

21. Fadare, O.O.; Okoffo, E.D. Covid-19 face masks: A potential source of microplastic fibers in the environment. Sci. Total Environ. 2020, 737, 140279. [CrossRef] [PubMed]

22. Fubini, F. Covid la Curva Delle Mascherine: Perché i Poveri Rischiano di Più, Corriere Della Sera-Economic Section. Available online: https:/ / www.corriere.it/economia/consumi/20_ottobre_16/covid-italia-abbiamo-abbassato-guardia-dimostra-quest o-dato-34b22d92-0f99-11eb-8d21-ff516c396863.shtml (accessed on 21 October 2020). 